\title{
Behavioural Adaptation for the Thermal Comfort and Energy Saving in Japanese Offices
}

\author{
Hom B. Rijal ${ }^{\text {1a }}$, Michael A. Humphreys ${ }^{2}$, J. Fergus Nicol ${ }^{2}$ \\ ${ }^{1}$ Department of Restoration Ecology \& Built Environment, Tokyo City University, Japan \\ ${ }^{2}$ School of Architecture, Oxford Brookes University, UK \\ Corresponding author: ${ }^{a}$ rijal@tcu.ac.jp
}

Received: Dec 16, 2018

Revised: March 15, 2019

Accepted: March 17, 2019

\begin{abstract}
Office workers use a variety of adaptive opportunities to regulate their indoor thermal environment. The behavioural adaptations such as window opening, clothing adjustments, and use of heating/cooling are important factors for adaptive thermal comfort. It is well-known that they are the most important contributors in the adaptive thermal comfort model. Thus, if we understand the behavioural adaptation properly, we can explain the mechanism of the adaptive model. The indoor thermal environment is often adjusted using the air conditioning in Japanese office buildings to improve thermal comfort and productivity. Thus, it is necessary to conduct research on the behavioural adaptation in the offices because the occupant behavior is different from behaviour in dwellings. In order to record the seasonal differences in behavioural adaptation and to develop an adaptive algorithm for Japanese offices, we measured temperatures in 11 office buildings and conducted the thermal comfort and occupant behaviour survey for over a year. We collected 4,660 samples from about 1,350 people. The proportion of 'open window' in the free running mode (neither heating nor cooling being used) is significantly higher than that of the air conditioned mode. The behavioural adaptation is related to the outdoor air temperature. The behavioural adaptations such as windowopening, heating and cooling use predicted by regression analysis are in good agreement with the measured data. These findings can be applied to building thermal simulation to predict the behavioural adaptation and energy use in office buildings.
\end{abstract}

Keywords: Office buildings, Thermal comfort, Occupant behaviour, Window opening, Clothing adjustment, Heating and cooling use.

\section{Introduction}

People use a variety of adaptive opportunities to regulate their indoor thermal environment. The behavioural adaptations such as window opening, clothing adjustments, fan/heating/cooling use are some of the important factors for adaptive thermal comfort. It is well-known that they are the most important contributors in the adaptive thermal comfort model. Thus, if we understand the behavioural adaptation properly, we can explain the much of the mechanism of the adaptive model. In addition, the indoor thermal environment is often adjusted using the air conditioning in the Japanese office building to improve the thermal comfort and productivity. However, temperature 
control using window opening can reduce environmental impact by reducing the use of air conditioning as much as possible. Thus, it is necessary to conduct research on the behavioural adaptation in the offices because the occupant behavior is different from adaptive behaviour in dwellings.

A number of projects have researched occupant behaviour in offices $[2,5,9,13,21-25,27,30]$, university buildings $[28,29]$ and dwellings $[1,3,8,10,11,16-18,20]$. The occupant behaviour model developed for office buildings in other countries [22] may not apply to Japan and research about occupant behaviour is needed for Japanese offices, for results from one region of the world cannot be assumed to apply to another where there is a different culture and building design. Thermal simulation packages often assume a fixed schedule of window opening [23], so more realistic data on occupant behaviour will help to improve the thermal simulations and an adaptive algorithm becomes a useful passive design tool. In order to record the seasonal differences in behavioural adaptation and to develop an adaptive algorithm for Japanese offices, we measured temperatures in 11 office buildings and conducted occupant behaviour survey for over a year in the Tokyo and Yokohama areas of Japan.

\section{Methodology}

\subsection{Investigated Buildings}

In this survey, 11 office buildings were investigated in the Tokyo and Yokohama areas of Japan from August 2014 to October 2015 (see Table 1). These buildings are readily available in the investigated areas. The numbers of HVAC and mixed mode buildings are five and six respectively.

Table 1: Description of the investigated buildings [19]

\begin{tabular}{|c|c|c|c|c|c|c|c|c|c|}
\hline $\begin{array}{c}\text { Building } \\
\text { code }\end{array}$ & Location & $\begin{array}{c}\text { Building } \\
\text { construction }\end{array}$ & Mode & $\begin{array}{c}\text { HVAC } \\
\text { control }\end{array}$ & Window & $\begin{array}{c}\text { Natural } \\
\text { ventilation } \\
\text { opening }\end{array}$ & $\begin{array}{c}\text { Number of } \\
\text { floor* }\end{array}$ & $\begin{array}{c}\text { Investigated } \\
\text { floor* }\end{array}$ & $\begin{array}{c}\text { Number } \\
\text { of survey } \\
\text { months }\end{array}$ \\
\hline B1 & Tokyo & S, RC & HVAC & Central & Fixed & Manual & $14 \mathrm{~F}, 1 \mathrm{BF}$ & $4 \mathrm{~F}, 5 \mathrm{~F}$ & 13 \\
\hline B2 & Yokohama & RC & MX & Central & Openable & None & $6 \mathrm{~F}$ & $1 \mathrm{~F}, 5 \mathrm{~F}$ & 13 \\
\hline B3 & Tokyo & SRC & HVAC & Central & Fixed & None & $9 \mathrm{~F}$ & $3 \mathrm{~F}$ & 13 \\
\hline B4 & Yokohama & S, RC & MX & Local & Openable & None & $2 \mathrm{~F}$ & $1 \mathrm{~F}, 2 \mathrm{~F}$ & 13 \\
\hline B5 & Yokohama & RC, SRC & MX & Local & Openable & None & $7 \mathrm{~F}, 2 \mathrm{BF}$ & $5 \mathrm{~F}$ & 13 \\
\hline B6 & Yokohama & S, RC & MX & Local & Openable & None & $2,1 \mathrm{BF}$ & $1 \mathrm{~F}$ & 13 \\
\hline B7 & Tokyo & RC & MX & Local & Openable & None & $4 \mathrm{~F}, 1 \mathrm{BF}$ & $1 \mathrm{~F}, 4 \mathrm{~F}$ & 13 \\
\hline B8 & Tokyo & RC & MX & Local & Openable & None & $3 \mathrm{~F}, 1 \mathrm{BF}$ & $1 \mathrm{~F}$ & 13 \\
\hline B9 & Tokyo & RC & HVAC & Central & Fixed & None & $8 \mathrm{~F}, 3 \mathrm{BF}$ & $8 \mathrm{~F}$ & 13 \\
\hline B10 & Tokyo & S, SRC, PCa & HVAC & Central & Fixed & Automatic & $10 \mathrm{~F}, 1 \mathrm{BF}$ & $6 \mathrm{~F}, 7 \mathrm{~F}$ & 12 \\
\hline B11 & Tokyo & S, SRC, RC & HVAC & Central & Fixed & None & $24 \mathrm{~F}, 4 \mathrm{BF}$ & $13 \mathrm{~F}, 21 \mathrm{~F}$, & $12 * *$ \\
\hline
\end{tabular}

S: Steel, RC: Reinforced Concrete, SRC: Steel Reinforced Concrete, HVAC: Heating, ventilation and air conditioning, MX: Mixed mode (heating in winter and cooling in summer), *: The floor is counted by American system, F: Floor, BF: Basement floor, **: We have divided the floors in A, B \& C groups (A: 22F, B: 21F, 23F, C: 11F, 12F, 13F) for monthly survey and each group is visited every 3 months i.e. each season. One small room of $21 \mathrm{~F}$ is visited only once. 
The type of mixed mode building is change-over. All mixed mode buildings have openable windows, and most of them (B4 B8) are university office buildings. Generally, people open the windows in spring and autumn, and use cooling and heating in summer and winter. Two HVAC buildings have both manual and automatic natural ventilation openings. The surveyed floors were selected based on availability of occupants and permission given by the building managers.

\subsection{Thermal Comfort and Occupant Behaviour Survey}

Thermal comfort surveys were conducted and corresponding thermal measurements made in offices [19]. The indoor air temperature, globe temperature, relative humidity and air movement were measured $1.1 \mathrm{~m}$ above floor level, away from direct sunlight, using a data logger (Fig. 1, Table 2). Outdoor air temperature and relative humidity were obtained from the nearest meteorological station. The thermal comfort survey was conducted in Japanese. The subjective scales are shown in Table 3. The ASHRAE scale is frequently used to evaluate the thermal sensation vote (TSV), but the words 'warm' or 'cool' imply comfort in Japanese, and thus the modified thermal sensation vote (mTSV) is also used to evaluate the thermal sensation (Table 3 ). To avoid a possible misunderstanding of 'neutral', it was explained in the questionnaire as 'neutral (neither hot nor cold)'. It is also said that the optimum temperature occurs on the cooler side in summer and on the warmer side in winter [12].

We conducted both transverse and longitudinal surveys in open-plan offices. This paper analyses only the data from the transverse surveys. Transverse surveys were conducted 1 day each month by researchers visiting each building with measurement instruments and with questionnaires filled by each subject. On each visit, one set of responses was collected from each subject. As for the method of collecting the data, the instruments were set up on the office table, and questionnaires distributed to all people seated near to the instruments (Fig. 1). While people were filling the questionnaire, the researcher recorded the common environmental controls and the physical data from them. Window opening, heating use and cooling use were recorded in binary form at the time of completing the questionnaire $(0=$ window closed or heating/cooling off, $1=$ window open or heating/cooling on). We collected 4,660 thermal comfort votes from about 1350 people.

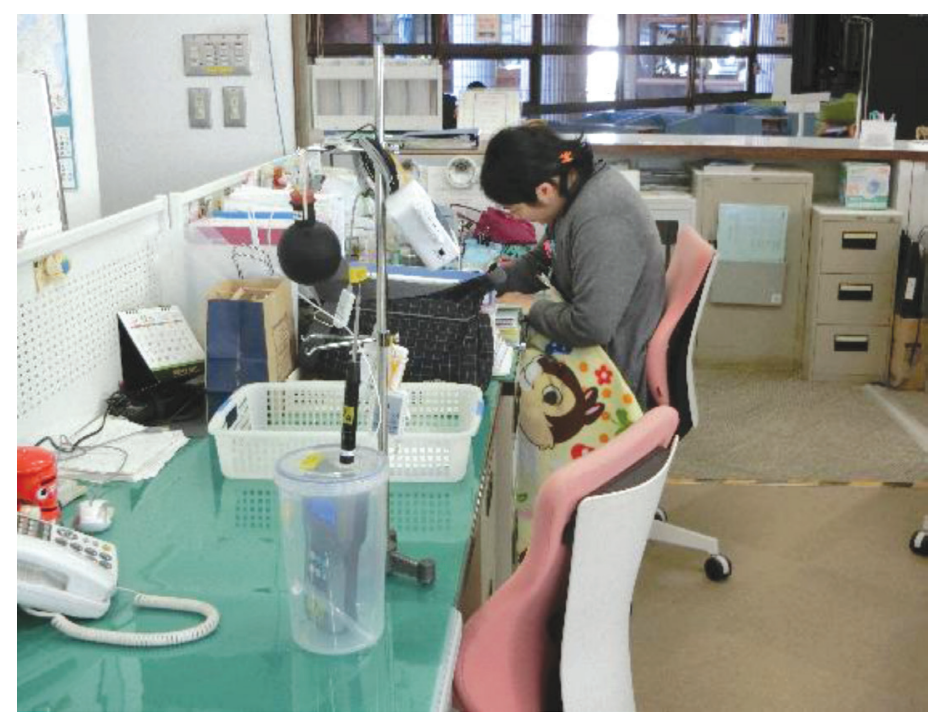

Fig. 1: Photograph of the instrumentation and a subject completing the thermal comfort survey 
Table 2: Description of the instruments

\begin{tabular}{|c|c|c|c|}
\hline Parameter Measured & Trade Name & Range & Accuracy \\
\hline $\begin{array}{c}\text { Air temp., Humidity, } \\
\mathrm{CO}_{2}\end{array}$ & TR-76Ui & $\begin{array}{c}0 \text { to } 55^{\circ} \mathrm{C}, 10 \% \text { to } 95 \% \mathrm{RH}, 0 \\
\text { to } 9,999 \mathrm{ppm}\end{array}$ & $\begin{array}{c} \pm 0.5^{\circ} \mathrm{C}, \\
\pm 5 \% \mathrm{RH}, \pm 50 \\
\mathrm{ppm} \\
\pm 0 .{ }^{\circ} \mathrm{C}\end{array}$ \\
\hline \multirow{2}{*}{ Globe temp. } & Tr-52i & -60 to $155^{\circ} \mathrm{C}$ & - \\
\cline { 2 - 4 } & SIBATA $080340-75$ & $\begin{array}{c}\text { Black painted } 75 \mathrm{~mm} \text { diameter } \\
\text { globe }\end{array}$ & $\pm 0.02 \mathrm{~m} / \mathrm{s}$ \\
\hline Air movement & Kanomax, $6543-21$ & 0.01 to $5.00 \mathrm{~m} / \mathrm{s}$ & $\pm 5 \%$ \\
\hline Illuminance & TR-74Ui & 0 to $130 \mathrm{klx}$ & \\
\hline
\end{tabular}

Table 3: Scale of modified thermal sensation vote (mTSV)

\begin{tabular}{|l|l|}
\hline No. & mTSV \\
\hline 1 & Very cold \\
\hline 2 & Cold \\
\hline 3 & Slightly cold \\
\hline 4 & Neutral (neither hot nor cold) \\
\hline 5 & Slightly hot \\
\hline 6 & Hot \\
\hline 7 & Very hot \\
\hline
\end{tabular}

\subsection{Estimating the Comfort Temperature}

Comfort temperatures (the estimated temperature corresponding to 'neutral' on the scale) were obtained from the votes on the mTSV scale using the Griffiths' method $[4,6,7,14,15,25,26]$.

$$
T_{c}=T_{g}+(4-\mathrm{mTSV}) / \mathrm{a}^{*}
$$

$T_{c}$ is the estimated comfort temperature using the Griffiths' method $\left({ }^{\circ} \mathrm{C}\right), T_{g}$ is the indoor globe temperature $\left({ }^{\circ} \mathrm{C}\right)$ and $\mathrm{a}^{*}$ is the assumed coefficient of dependence of the vote on the room temperature. In this analysis a* is taken to be 0.50 votes per degree $\mathrm{K}$, as found from analyses of field-study data worldwide [6,7] and from Japan [19].

\subsection{Estimating the Occupant Behaviour}

Nicol and Humphreys [13] made use of logistic analysis to predict occupant control behaviour in naturally ventilated buildings. We have adopted this method here, using SPSS version 23 for the calculations. The relationship between the probability of windows being open or heating use or cooling use (p) and the outdoor air temperature $\left(T_{o}\right)$ is of the form:

$$
\begin{aligned}
& \operatorname{logit}(\mathrm{p})=\log \{\mathrm{p} /(1-\mathrm{p})\}=\mathrm{b} T_{o}+\mathrm{c} \\
& \mathrm{p}=\exp \left(\mathrm{b} T_{o}+\mathrm{c}\right) /\left\{1+\exp \left(\mathrm{b} T_{o}+\mathrm{c}\right)\right\}
\end{aligned}
$$

where exp (exponential function) is the base of the natural logarithm, $b$ is the regression coefficient for $T_{o}$ and $\mathrm{c}$ the constant in the regression equation. 


\section{Results and Discussion}

The data were divided into three groups. If heating was in use at the time of the survey visit, the data were classified as being in the heating mode (HT). If cooling was in use at the time of the visit, the data were classified as being in the cooling mode (CL). If neither heating nor cooling were in use, the data were classified as being in the free-running mode (FR). The CL and HT modes are distinct groups of data (generally CL used in summer and HT is used in winter), and need to be analysed separately. Thus the classification differs from that used in the CIBSE Guide, and in current standards ISO Standard EN 15251 and ASHRAE Standard 55. The mixed (MX) mode includes all of these three modes.

\subsection{Outdoor and Indoor Temperature}

The mean outdoor air temperatures during the voting were $20.7^{\circ} \mathrm{C}, 24.9^{\circ} \mathrm{C}$ and $10.4^{\circ} \mathrm{C}$ for $\mathrm{FR}$, CL and HT modes respectively [19]. The globe temperature is highly correlated with the indoor air temperature, and so the results can be presented using the indoor globe temperature alone [19]. The mean globe temperatures during the voting were $25.0^{\circ} \mathrm{C}, 25.9^{\circ} \mathrm{C}$ and $23.8^{\circ} \mathrm{C}$ for $\mathrm{FR}, \mathrm{CL}$ and HT modes respectively [19]. The Japanese government recommends indoor temperature of $20^{\circ} \mathrm{C}$ in winter and $28{ }^{\circ} \mathrm{C}$ in summer respectively. The results show that the mean indoor temperatures during heating and cooling were quite different from those recommended. As shown in the Fig. 2, the seasonal range of the mean indoor temperature was quite small (about $5 \mathrm{~K}$ ), while there was a wide seasonal range of the monthly mean outdoor temperature (about 10K).

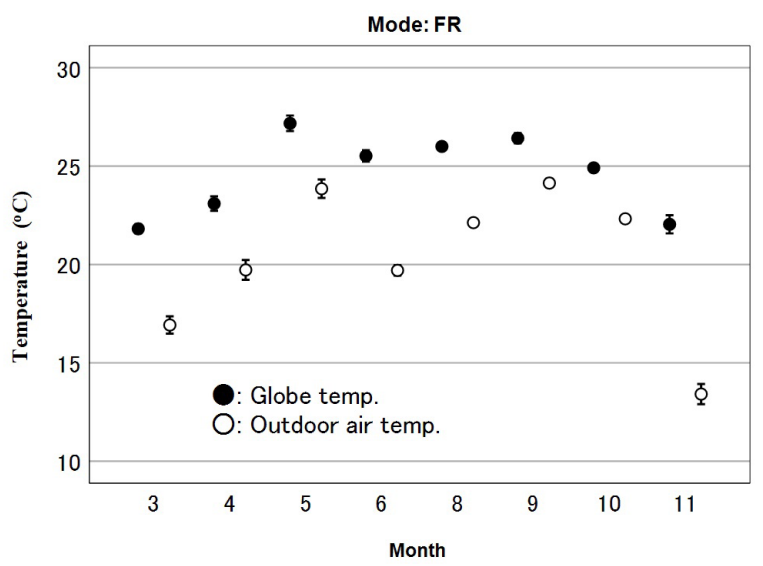

Fig. 2: Monthly mean globe temperature and outdoor air temperature (at $95 \%$ confidence level: Mean \pm 2 S.E.)

\subsection{Window Opening}

\subsubsection{Status of window opening}

The mean 'open window' for all data is $0.23(\mathrm{n}=1230)$. When we compared by building, the mean value ranged from 0.02 to 0.51 . The mean window opening is $0.68(n=399), 0.03(n=330)$ and $0.01(\mathrm{n}=501)$ for FR, CL and HT modes respectively. Interestingly, the mean window opening in UK office buildings was 0.70 in NV mode and 0.04 in AC mode [23]. The mean windows open in Pakistan office and commercial buildings was 0.33 in NV mode [25]. The results showed that the mean windows open is close to the UK and higher than the Pakistan. As the window opening is 
very low in the CL and HT modes, we shall limit the analysis to the FR mode.

\subsubsection{Season and month}

The proportion of open windows is highest in summer and lowest in spring (Fig. 3(a)). The proportion of open windows in autumn is significantly higher than that in spring. However, the indoor and outdoor air temperatures in autumn are slightly higher than that of spring (Fig. 3(b)), so more window opening would be expected. Evidently, the proportion of open windows gradually increases towards the summer months (Fig. 4). Conversely, it gently decreases towards the winter months as indoor or outdoor air temperature varies (Fig. 2).
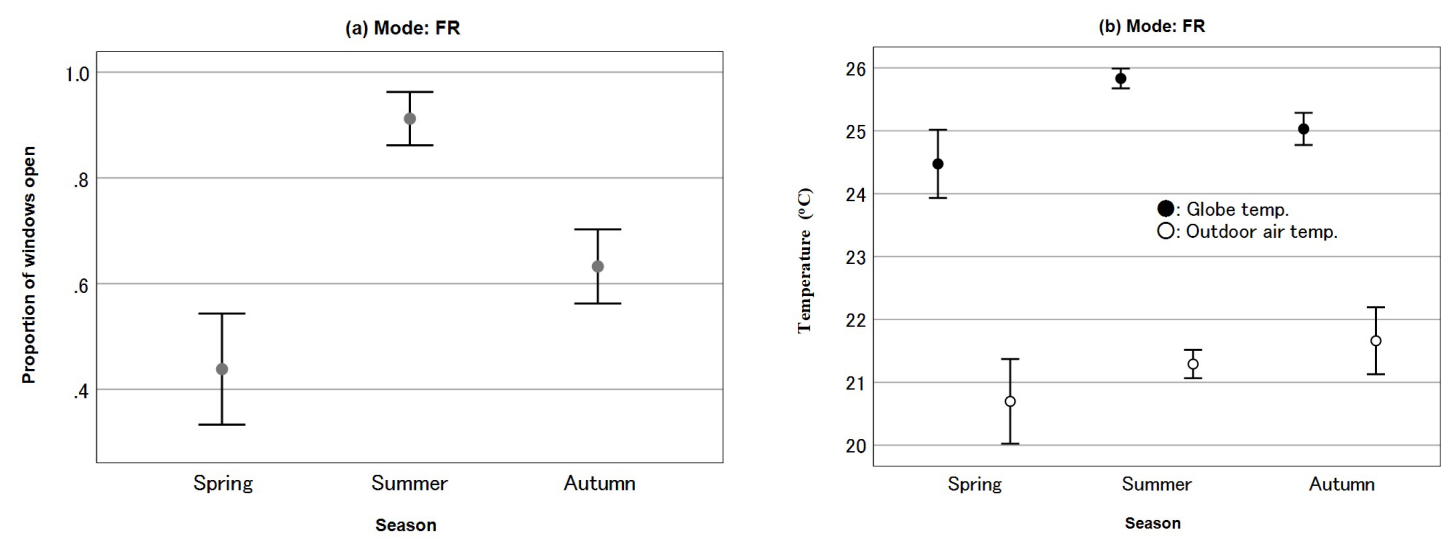

Fig. 3: The proportion of open windows, globe temperature and outdoor air temperature in each season

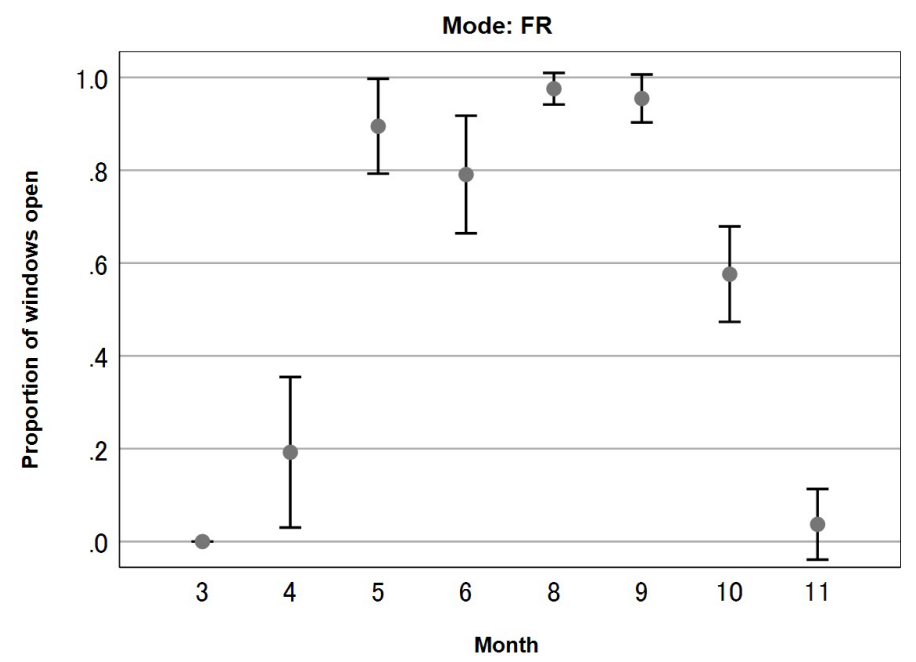

Fig. 4: The proportion of open windows in each month (at 95\% confidence level: Mean \pm 2 S.E.)

\subsubsection{Cooling effect of the open window}

The potential of the open window is further analyzed in the context of indoor globe temperature or comfort temperature. The mean globe temperature for window open is $25.8{ }^{\circ} \mathrm{C}$ which is 1.9 
$\mathrm{K}$ higher than that of the case of window closed (Fig. 5(a)). The mean comfort temperature for window open is $25.4{ }^{\circ} \mathrm{C}$ which is $1.5 \mathrm{~K}$ higher than that of the case of window closed (Fig. $5(\mathrm{~b})$ ). Brager et al. [2] found 1.5 K higher comfort temperature for the people in office buildings with access to window operation than the group without such access. It is interesting to note that we have also found the same results in Japanese offices. The temperature difference for the windows open and closed in spring is higher than in autumn (Fig. 5). The results showed that window opening is effective to increase the comfort temperature.
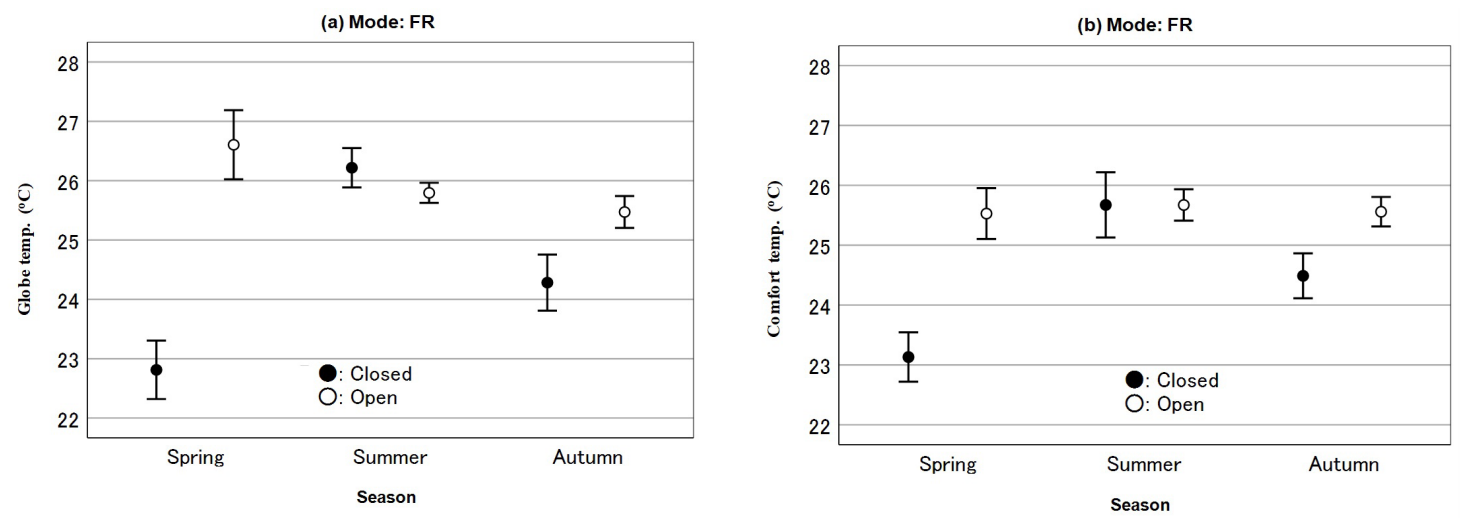

Fig. 5: Seasonal variation of globe and comfort temperature for windows open and closed (at 95\% confidence level: Mean \pm 2 S.E.)

\subsubsection{Development of an algorithm to predict window opening behaviour}

In the previous sections, we analyzed the window opening behaviour based on field data and confirmed some general behavioural trends, but no attempt was made to predict the occupant behaviour in Japanese offices. Such predictions are needed for the thermal simulation of buildings. The following regression equations were obtained for all data in between the windows open and the outdoor air temperature:

$$
\operatorname{logit}(\mathrm{p})=0.507 T_{o}-10.0\left(\mathrm{n}=399, \mathrm{R}^{2}=0.27, \text { S.E. }=0.059, \mathrm{p}<0.001\right)
$$

where $n$ is number of data, $\mathrm{R}^{2}$ is Cox and Snell $\mathrm{R}^{2}$, S.E. is standard error of the regression coefficient and $\mathrm{p}$ is significance-level of the regression coefficient.

In this study a regression coefficient of 0.507 is obtained when the open window and outdoor air temperature are regressed. Kyoto [11] and UK [23] studies returned the regression coefficients of 0.119 and 0.181 respectively when open window is regressed with outdoor air temperature. It seems that the regression coefficient of this research is higher than the previous research. As shown in the Fig. 6(a), the proportion of the windows open rises as the outdoor temperature rises. In order to analyze the window opening behaviour in MX mode, we conducted a Gaussian regression analysis using the following equations. We used this method because, due to cooling use, the proportion of window-opening gradually decreases above a certain outdoor temperature. Due to heating use, the proportion of window-opening is also gradually decreased below a certain outdoor temperature.

$$
\mathrm{p}=\mathrm{Ae}^{\mathrm{Y}}
$$




$$
\mathrm{Y}=\left\{-\left(T_{0}-\mu\right)^{2} / 2 \sigma^{2}\right\}
$$

where $\mathrm{A}$ is height of the peak, $\mu$ is $\mathrm{x}$ value of the center of the peak, $\sigma$ is controlling peak's width; A, $\mu$ and $\sigma$ being constants. The regression equation of the proportion of open windows $\left(P_{w}\right)$ obtained by using Gaussian function is shown in equation (7).

$$
P_{w}=0.763 \exp \left\{-\left(T_{o}-23.1\right) 2 / 0.564\right\} \quad(\mathrm{n}=1230)
$$

The regression line which is calculated by equation (7) is shown in Fig. 6 (b). The temperature that results in the maximum value of $P_{w}$ is about $23^{\circ} \mathrm{C}$.

(a) FR

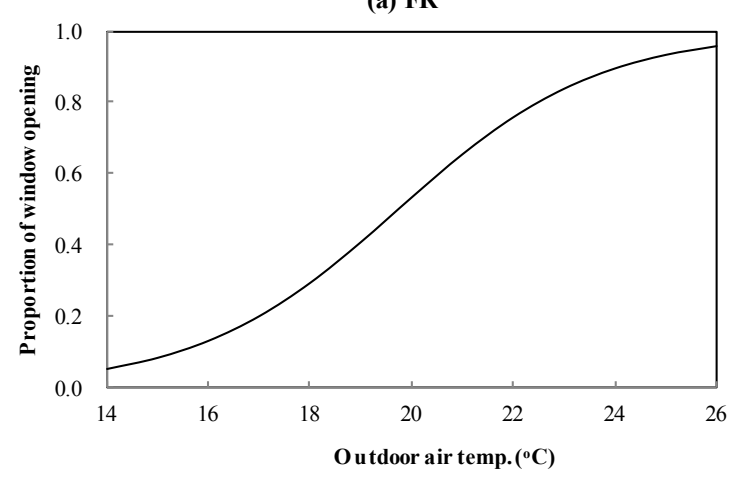

(b) MX mode

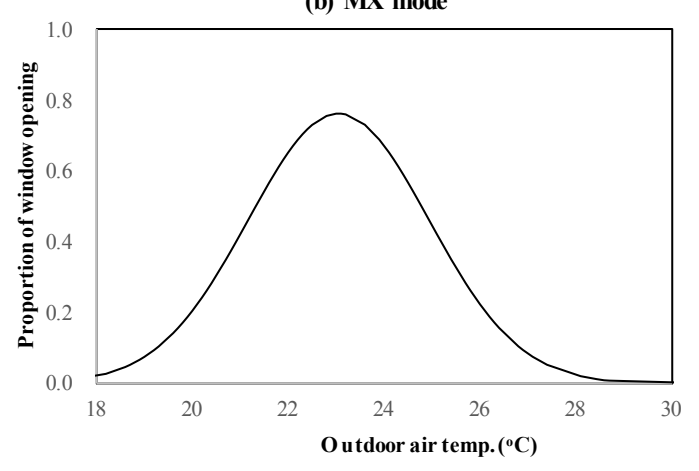

Fig. 6: Relation between the window opening and outdoor air temperature

\subsection{Clothing Adjustments}

Fig. 7 shows the mean clothing insulation in each mode. The mean clothing is 0.67 clo in FR mode which is slightly higher than CL mode and lower than HT mode. The results show that people adjusted their clothing considerably in each mode.

In order to predict the clothing insulation, regression analysis of the clothing insulation and outdoor air temperature is conducted. Fig. 8 shows the relation between the clothing insulation and outdoor air temperature with the $95 \%$ confidence interval of the individual clo-values in MX mode. The following regression equations were obtained between the clothing insulation $\left(I_{c l}\right.$, clo) and outdoor temperature.

$$
\begin{array}{ll}
\text { FR } & I_{c l}=-0.030 T_{o}+1.3\left(\mathrm{n}=419, \mathrm{R}^{2}=0.27, \text { S.E. }=0.002, \mathrm{p}<0.001\right) \\
\text { CL } & I_{c l}=-0.006 T_{o}+0.8\left(\mathrm{n}=2488, \mathrm{R}^{2}=0.08, \text { S.E. }=0.0004, \mathrm{p}<0.001\right) \\
\text { HT } & I_{c l}=-0.007 T_{o}+0.9\left(\mathrm{n}=1692, \mathrm{R}^{2}=0.01, \text { S.E. }=0.002, \mathrm{p}<0.001\right) \\
\text { MX } & I_{c l}=-0.014 T_{o}+1.0\left(\mathrm{n}=4599, \mathrm{R}^{2}=0.30, \text { S.E }=0.0003, \mathrm{p}<0.001\right)
\end{array}
$$

$\mathrm{R}^{2}$ is coefficient of determination. The regression coefficients are negative for all equations. It shows that the clothing insulation decreases when outdoor air temperature is increased. 


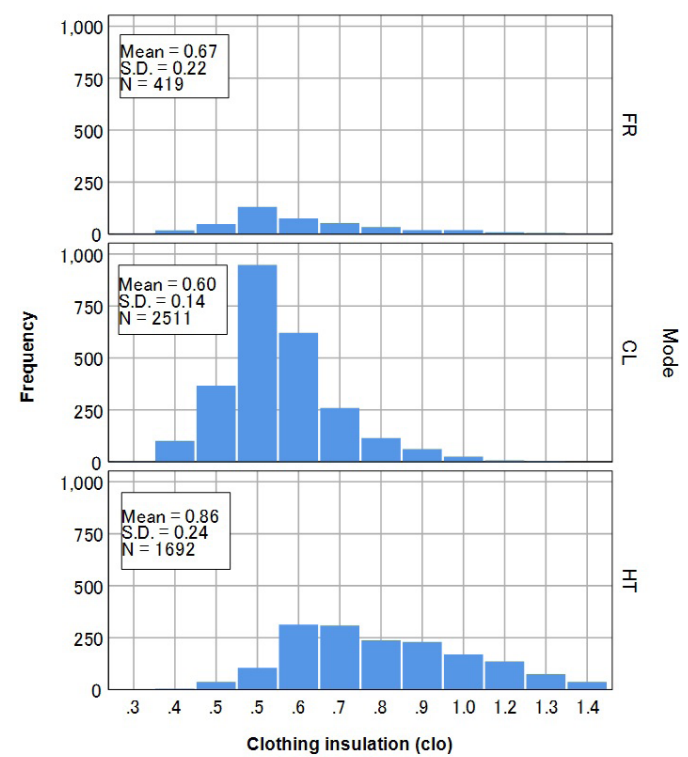

Fig. 7: Distribution of clothing insulation

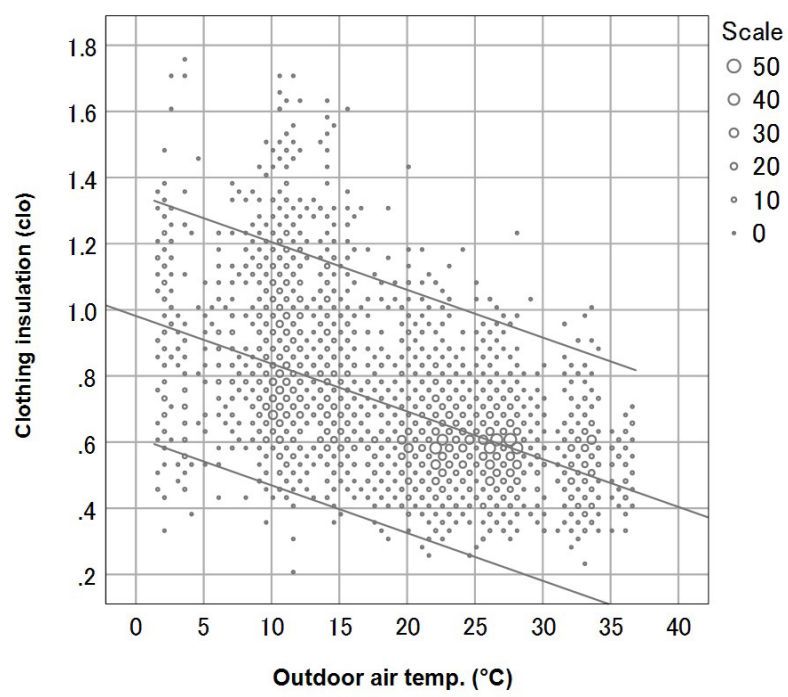

Fig. 8: Relation between the clothing insulation and outdoor air temperature

\subsection{Heating and Cooling Use}

In this section, we will analyze the active behaviour such as heating and cooling use. These behaviours are needed for the thermal simulation of buildings. The following regression equations were obtained for all data in between the heating use or cooling use and the outdoor air temperature:

$\begin{array}{ll}\text { Heating } & \operatorname{logit}(\mathrm{p})=-0.839 T_{o}+13.6\left(\mathrm{n}=1241, \text { S.E } .=0.055, \mathrm{R}^{2}=0.66, \mathrm{p}<0.001\right) \\ \text { Cooling } & \operatorname{logit}(\mathrm{p})=0.359 T_{0}-8.5\left(\mathrm{n}=1241, \text { S.E. }=0.024, \mathrm{R}^{2}=0.37, \mathrm{p}<0.001\right)\end{array}$ 
These equations are presented in the Fig. 9. The proportion of the heating use rises as the outdoor temperature decreases, and the proportion of the cooling use rises as the outdoor temperature increases.
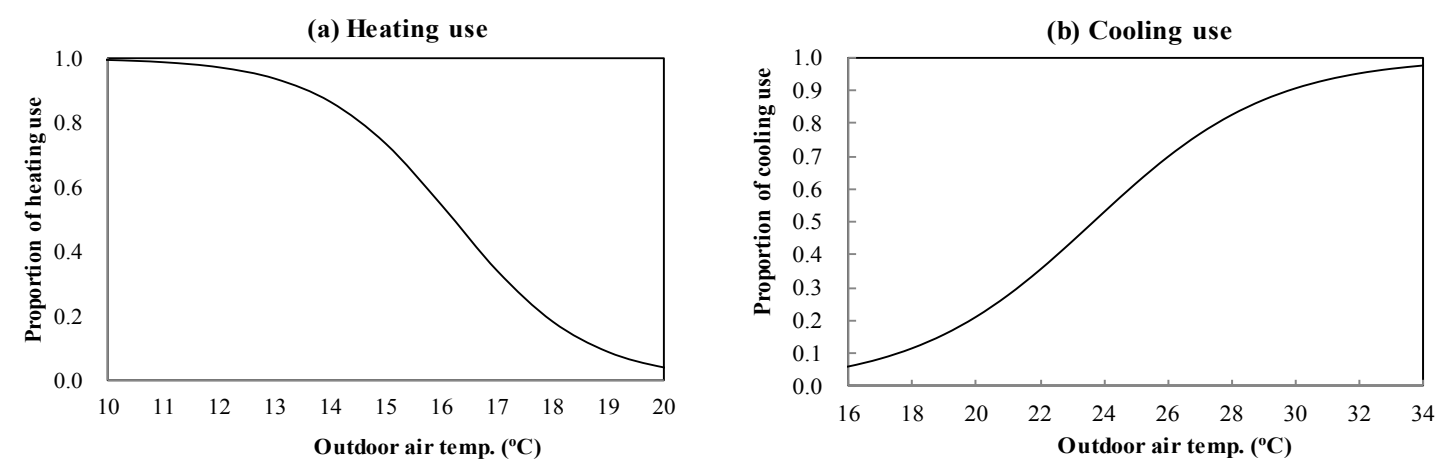

Fig. 9: Relation between the heating use or cooling use and outdoor air temperature

\section{Conclusions}

A thermal comfort survey and occupant behaviour survey in the Tokyo and Yokohama areas of Japan were conducted more than a year in 11 office buildings. The following results were found:

- The proportion of 'open window' in the free running mode (neither heating or cooling being used) is significantly higher than that of the air conditioned mode.

- The behavioural adaptations (window opening, clothing adjustments, heating/cooling use) are related to the outdoor air temperature.

- The behavioural adaptation predicted by regression analysis is in good agreement with the measured data. These findings can be applied to building thermal simulation to predict the behavioural adaptation, indoor temperature and energy use in office buildings.

Acknowledgments: We would like to thank to all the people who participated in the survey, to the Gotoh Educational Corporation, Hulic Co., Ltd., Nikken Sekkei Ltd., Panasonic Corporation, Tokyo City University, Tokyu Fudosan Next Generation Engineering Center Inc., Tsuzuki Ward for their cooperation and to all students for data entry. This research was supported by Grant-in-Aid for Scientific Research (C) Number 17K06681.

\section{References}

[1] Asawa T, Hoyano A, Takezawa H and Shimizu K (2005), Analysis of the behavioral characteristics of both window opening and air conditioning use at detached houses: Relationship between outdoor microclimate and residents' living open to outdoor part 2, J. Environ., Eng., AIJ 593 : 87-94.

[2] Brager GS, Paliaga G and de Dear R (2004), Operable windows, personal control, and occupant comfort, ASHRAE Transactions 110(2): 17-35.

[3] Dick JB and Thomas DA (1951), Ventilating research in occupied houses. JIHVE 19 : 306-326.

[4] Griffiths ID (1990), Thermal comfort in buildings with passive solar features: Field studies, Report to the Commission of the European Communities, EN3S-090, UK. 
[5] Haldi F, Robinson D (2010), On the unification of thermal perception and adaptive actions, Building and Environment 45(11) : 2440-2457.

[6] Humphreys MA, Nicol JF and Roaf S (2016), Adaptive thermal comfort: Foundations and analysis, Routledge.

[7] Humphreys MA, Rijal HB and Nicol JF (2013), Updating the adaptive relation between climate and comfort indoors; new insights and an extended database, Building and Environment $\mathbf{6 3}$ : 40-55.

[8] Imagawa H. and Rijal HB (2015), Field survey of the thermal comfort, quality of sleep and typical occupant behaviour in the bedrooms of Japanese houses during the hot and humid season, Architectural Science Review 58(1) : 11-23

[9] Kim J, Kawaguchi T and Tanabe S (2009), The behavioral characteristic of office workers use of natural ventilation window, J. Environ. Eng., AIJ 74 (643) : 1075-1082.

[10] Kubota $\mathrm{T}$ (2007), A field survey on usage of air-conditioners and windows in apartment houses in Johor Bahru city, J. Environ. Eng., AIJ 616: 83-89.

[11] Majima M, Umemiya N, Yoshida H and Rijal HB (2007), Thermal comfort of traditional narrow alleys in an urban area: Survey for Nishijin district in Kyoto, J. Environ., Eng., AIJ 622: 41-48.

[12] McIntyre DA (1980), Indoor climate, London: Applied Science Publishers, Ltd.

[13] Nicol JF and Humphreys MA (2004), A stochastic approach to thermal comfort - occupant behavior and energy use in buildings, ASHRAE Transactions 110(2): 554-568.

[14] Nicol JF, Humphreys MA and Roaf S (2012), Adaptive thermal comfort: Principles and Practice, Routledge.

[15] Nicol F, Jamy GN, Sykes O, Humphreys M, Roaf S and Hancock M (1994), A survey of thermal comfort in Pakistan toward new indoor temperature standards, Oxford Brookes University, Oxford England.

[16] Rijal HB (2018), Window opening behaviour in Japanese dwellings. pp. 271-282, In: Sustainable houses and living in the hot-humid climates of Asia. Eds.: Kubota T, Rijal HB and Takaguchi H, Springer.

[17] Rijal HB, Humphreys M and Nicol F (2015), Adaptive thermal comfort in Japanese houses during the summer season: Behavioral adaptation and the effect of humidity, Buildings 5(3) : 1037-1054

[18] Rijal HB, Humphreys MA and Nicol JF (2018), Development of a window opening algorithm based on adaptive thermal comfort to predict occupant behavior in Japanese dwellings, Japan Architectural Review 1(3): 310-321.

[19] Rijal HB, Humphreys MA and Nicol JF (2017), Towards an adaptive model for thermal comfort in Japanese offices, Building Research \& Information 45(7) : 717-729.

[20] Rijal HB, Honjo M, Kobayashi R and Nakaya T (2013), Investigation of comfort temperature, adaptive model and the window opening behavior in Japanese houses, Architectural Science Review, 56(1): 54-69.

[21] Rijal HB, Tuohy P, Humphreys MA, Nicol JF and Samuel A (2011), An algorithm to represent occupant use of windows and fans including situation-specific motivations and constraints, Building Simulation 4 (2) : 117-134.

[22] Rijal HB, Tuohy P, Humphreys MA, Nicol JF and Samuel A (2012), Considering the impact of situation-specific motivations and constraints in the design of naturally ventilated and hybrid buildings, Architectural Science Review 55(1) : 35-48.

[23] Rijal HB, Tuohy P, Humphreys MA, Nicol JF, Samuel A and Clarke J (2007), Using results from field surveys to predict the effect of open windows on thermal comfort and energy use in buildings, Energy and Buildings 39(7) : 823-836. 
[24] Rijal HB, Tuohy P, Nicol F, Humphreys MA, Samuel A and Clarke J (2008), Development of an adaptive window-opening algorithm to predict the thermal comfort, energy use and overheating in buildings, Journal of Building Performance Simulation 1 (1) : 17-30.

[25] Rijal HB, Tuohy P, Humphreys MA, Nicol JF, Samuel A, Raja IA and Clarke J (2008), Development of adaptive algorithms for the operation of windows, fans and doors to predict thermal comfort and energy use in Pakistani buildings, ASHRAE Transactions 114 (2) : 555-573.

[26] Rijal HB, Yoshida H and Umemiya N (2010), Seasonal and regional differences in neutral temperatures in Nepalese traditional vernacular houses, Building and Environment 45(12) : 2743-2753.

[27] Robinson D and Haldi F (2008), An integrated adaptive model for overheating risk prediction, Journal of Building Performance Simulation 1(1) : 43-55.

[28] Suzuki T, Umemiya N and Yoshida H (2002), Structure of the causes of window opening and closing behavior from summer to autumn: Survey on the students in study rooms in university campus, J. Archit. Plann. Environ. Eng., AIJ 556 : 91-98.

[29] Umemiya N and Yoshida H (2004), Survey on relationship between the ratio of window-opening area and the indoor and outdoor climate mainly for the season of natural ventilation, Transaction of Air-Conditioning and Sanitary Engineers of Japan 92 : 19-28.

[30] Yun GY and Steemers K (2008), Time-dependent occupant behaviour models of window control in summer, Building and Environment 43(9) : 1471-1482. 